\title{
EXTRAÇÃO DE ALUMINATO DE EMBALAGENS PLÁSTICAS METALIZADAS
}

\section{Carolina Inácio Portela ${ }^{1}$ \\ Liu Yao $\mathrm{Cho}^{2}$ \\ Andrea Santos Liu $^{3}$}

Resumo - O elevado volume de resíduos sólidos gerados atualmente suscita uma busca pelo reaproveitamento desses materiais a fim de minimizar os impactos socioambientais a que estão vinculados. O presente trabalho tem como objetivo a reciclagem de embalagens plásticas metalizadas, advindas do resíduo sólido, através da extração de alumínio (porção metálica) dessas embalagens, possibilitando o reaproveitamento das suas partes metálicas e poliméricas. A extração foi realizada imergindo-se as embalagens em soluções de hidróxido de sódio, cuja concentração da solução e a massa de plástico foram variadas. Foi estudada uma relação para otimizar o tempo de extração do alumínio em solução. Obteve-se a partir do processo de extração soluções de aluminato de sódio, que podem ser reutilizadas como coagulante para tratar águas residuárias de origem industrial. E o polímero resultante pode ser reutilizado como matéria prima na fabricação de novos produtos. Dessa forma, torna-se possível o reaproveitamento integral dessas embalagens, inserindo-as novamente ao ciclo produtivo.

Palavras-chave: Resíduos sólidos; Reciclagem; Embalagens plásticas metalizadas.

\footnotetext{
1 Engenharia Ambiental e Sanitária I Universidade do Vale do Paraíba, Brasil. E-mail: carol inacioportela@hotmail.com.

${ }^{2}$ FEAU, IP\&D, Universidade do Vale do Paraíba, Brasil. E-mail: liu@univap.br.

${ }^{3}$ Instituto Federal de Educação, Ciência e Tecnologia de São Paulo, Brasil. E-mail: andrealiu1@gmail.com.
} 